numerical method, and is orderly in his arrangement of facts. There is no attempt to discuss any of the problems of surgery, but merely to state the results of surgical experience. We learn in the preface that the book has been written for the student "when first entering on the study" of surgery. For such readers it is, in our opinion, singularly ill adapted. Put into such hands the book would be nothing more or less than a "cram." Such men want a clear discussion of the great principles of surgical pathology and therapeutics, and not a synopsis. The true use of this book is for men at the end of their student career, when, having firmly grasped surgical principles, they want to freshen their memories on the details of surgical injuries and diseases. Such men will find it a very useful help. We have noticed a few errors which have escaped Mr. Walsham's critical eye, but for a book of the kind the whole is done so well that we hardly like to refer to them.

$A$ Handhook of Diseases of the Skin, with especial reference to Diagnosis and Treatment. By RoBert LIVEING, A.M. and M.D. Cantab., F.R C.P. Lond., \&c. Fifth Edition, Revised and Enlarged. London: Longmans, Green, and Co. 1887.

Dr. LIVEING's little Handbook has deservedly found favour in the eyes of the profession, alike from the reputation and experience of the author, his excellent teaching, the clear, easy style in which the work is written, and the judgment and discrimination with which the matter is selected and arranged. In welcoming another edition, we may content ourselves with pointing out that the author has successfully striven to ensure that there should be no falling off in merit. Many articles bave been rewritten; the whole book bears marks of careful revision; separate articles have been added on Nomenclature, Classification, and Medicinal Eruptions, and a number of new ones introduced on sorre important diseases. We have read the new edition with much pleasure.

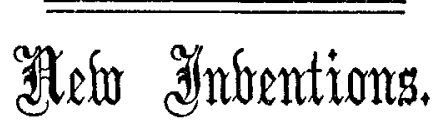

\section{A NEW GALVANIC CAUTERY INSTRUMENT,}

FOR USE IN NARROW CAVITIES, AND ESPECIALLY FOR THE TREATMENT OF INTRA-NASAL GROWTHS.

THE instrument delineated in the woodcut was designed by me for the application of the cautery to the deeper

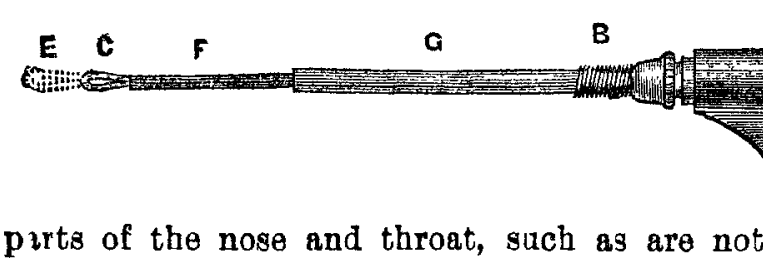
tasily reached by the loop of the érraseur or snare. It is important in such cases to apply the heated wire to very limited areas, and to a void contact with the septum and the healthy muc sus membrane. The instrument is held and worked easily in one hand, while the other is free for purposes of dilating the soft parts by means of the speculum. It is passed into the cavity which is illuminated by the mirror, and contact with the battery is made by pressure with the thumb on the button, $A$. At the same time that contact is made, the point $\mathrm{C}$ is protruded, and takes the position marked E. At $G$ is a metal sheath in which the platinum wire, $F$, is made to advance or recede. As soon as the cautery has acted sufficiently, pressure is removed from the button, $\Delta$, when the point $\mathrm{E}$ again recedes to its position, $c$, and at the same time, contact being cut off, the wire speedily becomes cool, and the instrument can then be removed without danger of cauterising the healthy parts. It is sometimes desirable to cover the part of the instrument between $\mathrm{B}$ and $\mathrm{C}$ with a quill, and thus still further protect the parts (the end of the quill at $c$ being open either laterally or terminally, and thus allowing the heated point to protrude and recede within a non-conducting channel). This instrument can be used with a three or four cell bichromate battery. When used after the application of cocaine to the nostrils there is seldom any bleeding, but if bleeding occurs the instrument must be withdrawn, and only again used after the blood has ceased to flow. When the cavity operated on is wide, a shield in the form of an ivory tube can be screwed on to the metal at $B$, but in narrower cavities a crowquill slipped over this part acts very well, and forms a very good means of protecting the mucous membrane from being scorched. This apparatus is made by Messrs. Krohne and Sesemann. I have found it very efficient, more especially for the treatment of polypus nasi after the bulk of the growths has been removed by the snare or galvanic écraseur.

\section{W. Spencer Watson.}

\section{AN IMPROVED FORM OF DISSECTING CASE.}

IT has often occurred to me that the usual form of dissecting case is scarcely as practical as it might bo. I have therefore suggested some alterations and additions to Messrs. Arnold and Sons, of West Smithfield, who have carried out all my suggestions. They are as follows :-

1. The substitution of four for the six knives generally furnished. Of these four, three are made much smaller

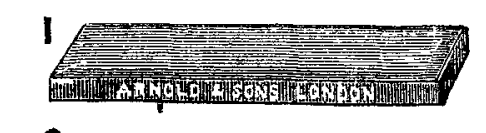

2

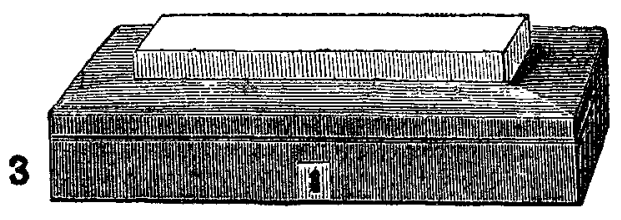

than usual, the ordinary pattern being too large for fine dissections until worn down. 2. The spring in the forceps is made specially weak, as otherwise the fingers soon get cramped and fatigued. 3. An extra pair of hooks is supplied, for with a single pair it is impossible to get counter-tension. Moreover, as hooks are easily borrowed, a small ivory indicator is affixed to the connecting ring for identification. 4. To prevent the bore of the blowpipe from becoming blocked a clearance plug is provided, which fits the tube and is kept inside until the former is wanted. 5. A small fine pair of scissors replaces the two large pairs generally supplied. 6. A card of ligature catgut occupies a small pocket inside the lid. 7. A good oilstone is fixed on the outside of the lid of the case, protected by a wooden cover. This enables the dissector to keep his knives in order without moving from bis seat or having to procure a stone. By the subtraction of the two knives and extra pair of scissors, the price remains the same or nearly the same as in the old form. G. Lindsay JoHnson, M.B., F.R.C.S. Stratford-place, $\mathbf{w}$. 